Editorials represent the opinions of the authors and not

necessarily those of the BMJ or BMA

\title{
Prolapsed intervertebral disc
}

\section{Evidence supports surgery after eight weeks if symptoms persist}

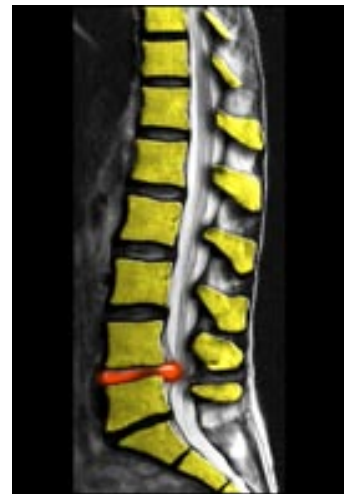

RESEARCH, pp 1351, 1355

Jeremy Fairbank professor of spinal surgery, Nuffield Department of Orthopaedic Surgery, Nuffield Orthopaedic Centre, Oxford OX37L jeremy.fairbank@ndos.ox.ac.uk Competing interests: None declared.

Provenance and peer review: Commissioned; not externally peer reviewed.

BMJ 2008;336:1317-8 doi: 10.1136/bmj.39583.438773.80
Prolapsed intervertebral disc is common-it is seen in up to a quarter of magnetic resonance scans and can be detected even in asymptomatic adults. ${ }^{1}$ Disc prolapse is genetically driven-twin studies indicate that at least $60 \%$ of the variance can be explained on genetic grounds and not by the commonly assumed environmental factors (work, trauma, exposure to excessive driving, smoking, and so on). ${ }^{2}$ In the linked randomised controlled trial, Peul and colleagues compare the effects of early surgery with conservative management at two years in 283 patients who have had sciatica for six to 12 weeks. $^{3}$ A second study by van den Hout and colleagues compares the costs of each approach. ${ }^{4}$

Current guidelines indicate that radicular pain should improve within six to eight weeks with conservative management. ${ }^{5}$ Surgery should be performed before eight weeks only in patients with progressive neurological deficit, which can be detected by magnetic resonance imaging. Some people will have radicular pain and no prolapse. Epidural local anaesthetic and steroids may benefit these patients, although the evidence base is weak. ${ }^{6}$

Management problems arise if severe pain lasts for longer than eight weeks. A few trials and many guidelines indicate that even at this stage many people will recover. Patients are more likely to have surgery if they have had one or more previous attacks of pain.

Commonly used non-operative measures such as manipulation, epidurals, physiotherapy, and analgesics have little effect on the course of sciatica. ${ }^{6}$ No features have been identified that can predict the time scale of recovery, except perhaps psychosocial factors. This is important because most people with radicular pain are of working age or are supporting young families. The risks of conservative treatment (as opposed to surgery) are low, although a few people will develop progressive neurology or cauda equina problems and $10 \%$ will have attacks in the future at the same site or another one. Again, we cannot predict who will have these complications.

Surgery is effective and alleviates at least $90 \%$ of radicular leg pain. It is less successful for back pain, and around $70 \%$ of people will continue to have long term back pain after surgery. Up to $10 \%$ of people will report more serious back pain and in some of these it will be disabling.

Surgery has no effect on recurrence, so the benefit of surgery is only short to medium term. Surgery is potentially dangerous. Up to $5 \%$ of people may have more pain and up to $1 \%$ may have neurological damage and will regret the decision to operate. ${ }^{6}$ Psychological factors are important both for persisting pain and the failure to meet the expectation of a good outcome, which surgeons should be aware of when advising treatment.

Peul and colleagues found no significant overall difference in disability scores during the first two years between early surgery and six months of conservative management. Leg pain improved significantly faster in patients who had early surgery. The relative short term global benefit of early surgery was no longer statistically significant by six months and continued to narrow between six months and two years.

The trial has some limitations. The non-operative arm is not evidence based-the evidence for all forms of non-operative treatment is poor, and many people get better spontaneously. The rate of transfer to the surgery arm from the conservative treatment arm was high (44\% switched to surgery compared with $30 \%$ in a previous trial ${ }^{7}$ ). This high rate of transfer reflects the large impact that this condition has on patients' quality of life and the difficulty of designing surgical versus non-surgical trials. The surgical technique used reflects current practice, but the aggressive curretage of the disc space used in the trial may be less effective than simply removing the herniated material. ${ }^{8} 9$

The design of the trial was ideal for coping with a potentially risky treatment for a largely benign but unpredictably malign condition. In the United States, the SPORT trial allowed patients to join a trial comparing surgery with non-operative care or to make their own choice about treatment. ${ }^{7}$ This study should be examined carefully by people designing randomised controlled trials because many would object to this type of "patient choice" protocol, which was designed to accommodate patients' reluctance to be randomised. The results supported the use of surgery.

Peul and colleagues' trial is similar in design to another trial done in the United Kingdom, which has never been fully published, but which had similar findings. ${ }^{10}$ Weber reported the first randomised controlled trial of surgical treatment versus non-operative care, although it was poorly designed. ${ }^{6} 11$ This trial found that surgery was better than non-operative care. It has informed decision making during the past 30 years, ${ }^{6}{ }^{11}$ and it is still helpful despite its well recognised flaws. ${ }^{12}$

The economic evaluation of Peul and colleagues' trial found that because early surgery was associated with quicker recovery from sciatica it is likely to be more cost effective than prolonged conservative care. 
The estimated difference in healthcare costs of $€ 40000$ ( $£ 32000 ; \$ 62000$ ) or more per quality adjusted life year was considered acceptable and was compensated for by the difference in absenteeism.

The focus of Peul and colleagues' study is on health economics based on the intelligent system of bottomup procedure pricing used in Holland. Early surgery is a viable economic option and should be applied in the UK.

What research questions remain? Major gaps exist in our knowledge of the underlying mechanisms of disc degeneration and prolapse. Of the trials that are available, few have shown non-operative treatments can improve the course of sciatica. ${ }^{6}$ Further trials of the risks of curretage and of minimally invasive versus open techniques would also be helpful. Finally, injections of chymopapain may be effective for young people with disc prolapse, but it has been rejected for reasons that are not backed by science. ${ }^{13}$

This trial adds to the body of evidence supporting surgery eight weeks after onset of sciatica if symptoms persist. Patients should understand the arguments for and against surgery and their perceived pain should be severe enough to justify the risks.

1 Boden $\mathrm{S}$. The use of radiographic imaging studies in the evaluation of patients who have degenerative disorders of the lumbar spine. J Bone Joint Surg Am 1996;78:114-25.
2 Battie M, Videman T, Parent E. Lumbar disc degeneration: epidemiology and genetic influences. Spine 2004;29:2679-90.

3 Peul WC, van den Hout WB, Brand R, Thomeer RTWM, Koes BW. Prolonged conservative care versus early surgery in patients with sciatica caused by lumbar disc herniation: two year results of a randomised controlled trial. BMJ 2008 doi: 10.1136/bmj.a143.

4 Van den Hout WB, Peul WC, Koes BW, Brand R, Kievit J, Thomeer RTWM. Prolonged conservative care versus early surgery in patients with sciatica from lumbar disc herniation: cost utility analysis alongside a randomised controlled trial. BMJ 2008 doi: 10.1136 bmj.39583.709074.BE.

5 Committee ECCBM. European guidelines for the management of low back pain. Eur Spine J 2006;15(suppl 2):S125-7; www. backpaineurope.org.

6 Jordon J, Konstantinou K, Morgan TS, Weinstein J. Herniated lumbar disc. Clin Evid 2007http://clinicalevidence.bmj.com/ceweb/ conditions/msd/1118/1118.jsp.

7 Weinstein J, Tosteson T, Lurie J, Tosteson A, Hanscom B, Skinner J, et al. Surgical vs nonoperative treatment for lumbar disk herniation. The spine patient outcomes research trial (SPORT): a randomized trial. JAMA 2006;296:2441-50.

8 Barth M, Diepers M, Weiss C, Thome C. Two-year outcome after lumbar microdiscectomy versus microscopic sequestrectomy: part 2: radiographic evaluation and correlation with clinical outcome. Spine 2008;33:273-9.

9 Barth M, Weiss C, Thome C. Two-year outcome after lumbar microdiscectomy versus microscopic sequestrectomy: part 1 : evaluation of clinical outcome. Spine 2008;33:265-72.

10 Greenfield K, Egger M, Nelson RJ, Findlay GD, Sanford E. Microdiscectomy versus conservative treatment for lumbar disc herniation: a randomised clinical trial. Vancouver: ISSLS, 2003.

11 Weber H. Lumbar disc herniation: a controlled, prospective study with ten years of observation. Spine 1983;8:131-40.

12 Weber H. Spine update: the natural history of disc herniation and the influence of intervention. Spine 1994;19:2234-8.

13 FairbankJ. Chymopapain and chemonucleolysis. In: Herkowitz $\mathrm{H}$ Dvorak J, Bell G, Nordin M, Grob D, eds. The lumbar spine. 3rd ed. Philadelphia: Lippincott Williams and Wilkins, 2004:447-52.

\section{Deficiency of sunlight and vitamin D}

\section{Fortification of foods and advice on sensible sun exposure are urgently needed}

\section{PRACTICE, p 1371}

Michael F Holick professo

of medicine, physiology, and biophysics, Department

of Medicine, Section of

Endocrinology, Nutrition, and

Diabetes, Vitamin D, Skin and

Bone Research Laboratory,

Boston University Medical Center,

Boston, MA, USA

mfholick@bu.edu

Competing interests: MFH

receives research support from

the UV Foundation, National Dairy

Council, and National Institutes

of Health.

Provenance and peer review:

Commissioned; not externally

peer reviewed.

BMJ 2008;336:1318-9

doi: 10.1136/bmj.39581.411424.80
At the turn of the 20th century more than $80 \%$ of children living in the industrialised cities of the Western hemisphere had rickets. ${ }^{1}{ }^{2}$ Rickets became extremely rare in the United Kingdom, Europe, and United States after it was realised that exposure to ultraviolet light was the major source of vitamin $\mathrm{D}$, and after the fortification of milk and other foods with vitamin D. ${ }^{2}$ At least a billion people worldwide are estimated to be vitamin $\mathrm{D}$ deficient, mainly because of inadequate exposure to sunlight and inadequate fortification of food with vitamin D. ${ }^{13-5}$

Skin pigmentation absorbs ultraviolet light, thereby reducing vitamin $\mathrm{D}$ production; this can be a problem for certain racial groups who now live in the Northern hemisphere. Human breast milk contains very little vitamin $\mathrm{D}$ and women with vitamin $\mathrm{D}$ deficiency provide no vitamin $\mathrm{D}$ for their infant. Such infants will be at high risk of developing rickets if they are exclusively breast fed. Rickets is the most overt sign of severe vitamin D deficiency in Europe-around 1-5\% of children with vitamin $\mathrm{D}$ deficiency have skeletal signs of rickets and probably $10-25 \%$ of adults with vitamin D deficiency have symptomatic osteomalacia.

Vitamin D deficiency causes secondary hyperparathyroidism and increases destruction of the skeleton by precipitating or exacerbating osteopenia and osteoporosis. ${ }^{13}$ Raised parathyroid hormone concentrations induce phosphaturia and hypophosphataemia; this causes a mineralisation defect of the osteoid (osteomalacia). Unlike osteoporosis, which is a painless disease, rickets and the adult counterpart osteomalacia can cause non-specific aches and pains in bones and muscles, and severe muscle weakness. ${ }^{1} 67$

In the accompanying lesson of the week, Sievenpiper and colleagues present two cases of severe vitamin D deficiency where the classic causes (figure) and clinical consequences were misdiagnosed as fibromyalgia, chronic fatigue syndrome, or degenerative arthritis. ${ }^{16-8}$ Sievenpiper and colleagues note that severe secondary hyperparathyroidism causes osteoclastogenesis, which can look like isolated lytic lesions in the skeleton and can be misdiagnosed as metastatic disease ${ }^{8}$ or even Paget's disease. The proximal muscle weakness reported by the authors is a common feature of vitamin $\mathrm{D}$ deficiency, ${ }^{16-8}$ which can be misdiagnosed as multiple sclerosis or amyotrophic lateral sclerosis. ${ }^{1}$

So what are the beneficial effects of vitamin D? People who live at higher latitudes, have vitamin D deficiency, or lack exposure to the sun have an increased risk of many cancers (figure). ${ }^{13-5}$ Increasing the intake of vitamin D to 1000 IU a day reduces the risk of colorectal cancer and many other deadly cancers by 30-50\%. ${ }^{13-5}$ Vitamin D deficiency is also linked to cardiovascular disease. After adjusting for standard cardiovascular 
risk factors, one study found that the risk for the first cardiovascular event was $62 \%$ higher in people with vitamin $\mathrm{D}$ deficiency. ${ }^{9}$ Vitamin $\mathrm{D}$ deficiency has also been associated with autoimmune diseases, infectious diseases, and schizophrenia (figure). ${ }^{15} 910$

Vitamin D has so many health benefits because all tissues have vitamin D receptors. ${ }^{13-5}$ Vitamin D controls (directly or indirectly) more than 200 genes that regulate calcium and bone metabolism, modulate innate immunity, control cell growth and maturation, regulate the production of insulin and renin, induce apoptosis and inhibit angiogenesis. ${ }^{145910}$ Skin, brain, colon, breast tissue, and macrophages can produce 1,25-dihydroxyvitamin D. ${ }^{1} 45910$ Once produced, 1,25-dihydroxyvitamin $\mathrm{D}$ carries out its biological function(s) within the cell and then induces its own destruction. ${ }^{1} 25$-Hydroxyvitamin $\mathrm{D}$ concentrations (the measure of vitamin D status) vary greatly with the season. ${ }^{13-5}$

Excessive exposure to sunlight causes an estimated annual loss of 1.6 million disability adjusted life years (DALYs) $-0.1 \%$ of the total global disease burden in the year 2000. This compares with the loss of about 3.3 billion DALYs from bone disease caused by vitamin $\mathrm{D}$ deficiency as a result of too little exposure to sunlight. ${ }^{11}$ These figures do not take into account the other potential health benefits of sun exposure and vitamin D sufficiency in reducing other chronic diseases, which account for $9.4 \%$ of total global disease burden. Notably, non-melanoma skin cancers occur on the most sun exposed areas, such as the face and hands, whereas most melanomas occur on the areas least exposed to the sun. ${ }^{12}$ Intermittent and occupational sun exposure has been found to reduce the risk of malignant melanoma. ${ }^{1} 4512$

How should vitamin D deficiency be diagnosed and treated? Serum calcium concentrations are usually normal in people with vitamin D deficiency and 1,25-dihydroxyvitamin $\mathrm{D}$ values are normal or raised.

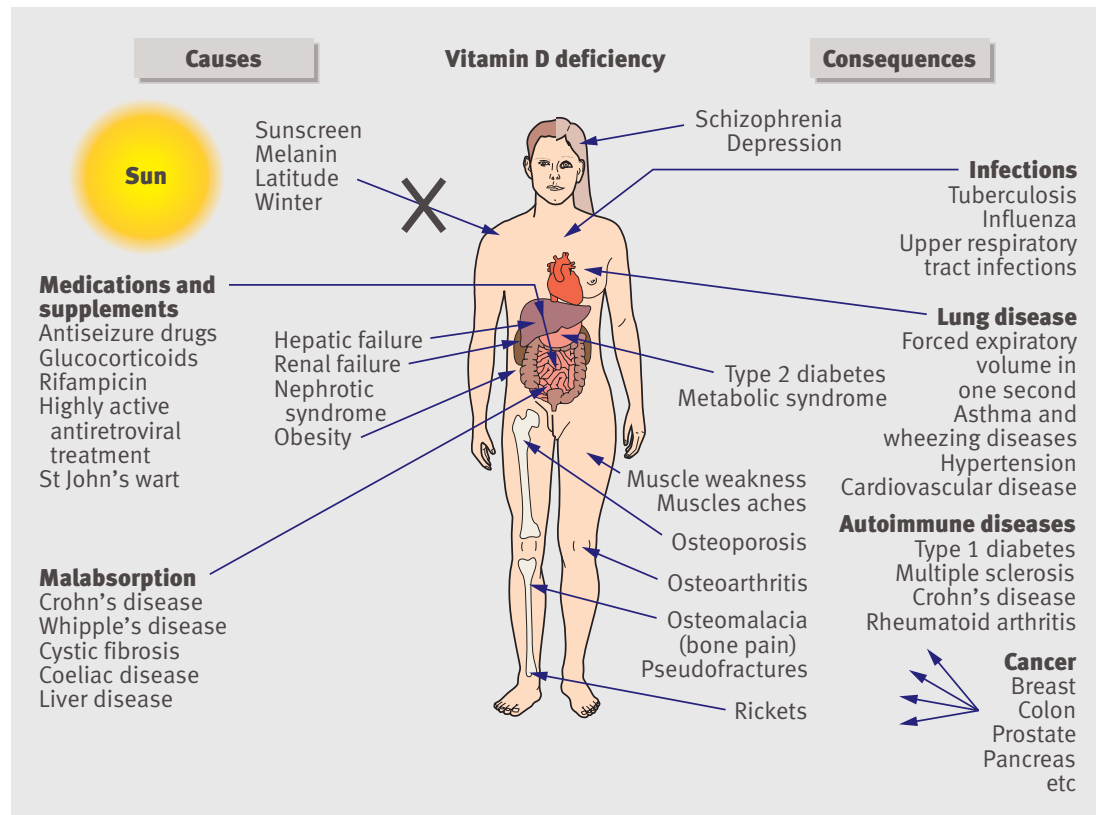

Causes and consequences of vitamin D deficiency
The only way to know a person's vitamin D status is to measure serum 25-hydroxyvitamin D concentrations. Sievenpiper and colleagues provided appropriate aggressive treatment of vitamin $\mathrm{D}$ deficiency with 300000 IU of intramuscular vitamin $\mathrm{D}_{3}$ monthly or $10000 \mathrm{IU}$ of oral vitamin $\mathrm{D}_{2}$ daily. ${ }^{8}$ Vitamin $\mathrm{D}_{2}(50000$ IU) once a week for eight weeks will correct vitamin D deficiency. ${ }^{1}$ To maintain vitamin D sufficiency, 50000 IU of vitamin $\mathrm{D}_{2}$ twice a month or $1000-2000$ IU of vitamin $\mathrm{D}_{3}$ a day is usually sufficient. ${ }^{13-5}$

Vitamin D intoxication is an extremely rare event and occurs from inadvertent or intentional vitamin D poisoning. Concentrations of 25-hydroxyvitamin D of 75-150 nmol/1 are recommended for health. Vitamin $\mathrm{D}$ intoxication occurs when concentrations are greater than $375 \mathrm{nmol} / \mathrm{l}$.

Although the health benefits of vitamin D sufficiency are clear, awareness of the dangers of vitamin D deficiency is lacking. People with vitamin D deficiency have no obvious symptoms until it is so severe that they develop osteomalacia; this is often misdiagnosed as fibromyalgia, so many doctors may not be aware of the problem. Public health campaigns that emphasise the insidious consequences of vitamin D deficiency on health are therefore needed. Regulatory health agencies also need to provide recommendations for sensible sun exposure, especially for ethnic minorities. They should also implement aggressive fortification of foods-supplementation should be increased from 100 IU per serving to at least 200 IU. The US, Canada, Sweden, and Finland already fortify milk with vitamin D but this policy should be extended to Europe. More foods, such as pasta, other dairy products, and orange juice should be fortified.

1 Holick MF. Vitamin D deficiency. N EnglJ Med 2007;357:266-81.

2 Hess AF, Unger LJ. The cure of infantile rickets by sunlight. JAMA 1921;77:39-41.

3 Bischoff-Ferrari HA, Giovannucci E, Willett WC, Dietrich T, DawsonHughes B. Estimation of optimal serum concentrations of 25-hydroxyvitamin D for multiple health outcomes. Am J Clin Nutr 2006;84:18-28.

4 Grant WB, Garland CF. The association of solar ultraviolet B (UVB) with reducing risk of cancer: multifactorial ecologic analysis of geographic variation in age-adjusted cancer mortality rates. Anticancer Res 2006;26:2687-99.

5 Moan J, Porojnicu AC, DahlbackA, Setlow RB. Addressing the health benefits and risks, involving vitamin D or skin cancer, of increased sun exposure. Proc Natl Acad Sci 2008;105:668-73.

6 Plotnikoff GA, Quigley JM. Prevalence of severe hypovitaminosis D in patients with persistent, nonspecific musculoskeletal pain. Mayo Clin Proc 2003;78:1463-70.

7 Erkal MZ, Wilde J, Bilgin Y, Akinci A, Demir E, Bodeker RH, et al. High prevalence of vitamin $D$ deficiency, secondary hyperparathyroidism and generalized bone pain in Turkish immigrants in Germany: identification of risk factors. Osteoporos Int 2006;17:1133-40.

8 Sievenpiper JL, McIntyre EA, Verrill M, Quinton R, Pearce SHS. Unrecognised severe vitamin D deficiency. BMJ 2008 doi: 10.1136/ bmj.39555.820394.B.

9 Wang TJ, Pencina MJ, Booth SL, Jacques PF, Engelsson E, Lanier K, et al. Vitamin D deficiency and risk of cardiovascular disease. Circulation 2008;117:503-11.

10 Adams JS, Hewison M. Unexpected actions of vitamin D: new perspectives on the regulation of innate and adaptive immunity. Nat Clin Pract Endocrinol Metab 2008;4:80-90.

11 Lucas RM, McMichael AJ, Armstrong BK, Smith WT. Estimating the global disease burden due to ultraviolet radiation exposure. Int] Epidemiol 2008 Feb 14 [Epub ahead of print].

12 Kennedy C, Bajdik CD, Willemze R, de Gruijl FR, Bavinck JN. The influence of painful sunburns and lifetime of sun exposure on the risk of actinic keratoses, seborrheic warts, melanocytic nevi, atypical nevi and skin cancer. J Invest Dermatol 2003;120:1087-93. 


\section{Treating migraine in the emergency department \\ Corticosteroids do not relieve acute pain but do reduce recurrence}

\section{RESEARCH, p 1359}

\section{Randolph W Evans clinical}

professor of neurology, Baylor

College of Medicine, Houston, TX

77004, USA

rwevans@pol.net

Competing interests: RWE is a

consultant or on the speakers

bureau (or both) of Abbott,

GlaxoSmithKline, Merck, Ortho-

McNeil, Pfizer, and Valeant.

Provenance and peer review:

Commissioned; not externally

peer reviewed.

BMJ 2008;336:1320

doi: $10.1136 / \mathrm{bmj} .39560 .696748 .80$
In the accompanying systematic review, Colman and colleagues assess the effectiveness of parenteral corticosteroids for treating acute severe migraine and preventing recurrence. ${ }^{1}$ In Western Europe and the United States, about $12 \%$ of adults experience migraine each year, and $63 \%$ of these people have one to four migraines a month. Most people have nausea and moderate to severe pain, which results in severe impairment or requires bed rest, and one third have vomiting. ${ }^{2}$ If untreated, these headaches last for four to 72 hours, with a median duration of 24 hours.

In the US, only $56 \%$ of affected patients have received a medical diagnosis of migraine and instead believe that they have sinus, tension, or stress headache. About half of these people use over the counter drugs, ${ }^{3}$ which are effective in up to $59 \%$ of cases. But even with seven different types of triptans and various ways of giving them, $25 \%$ of patients do not respond. ${ }^{4}$

When triptans are initially effective, the pain recurs in up to $40 \%$ of instances and a second dose may not be effective or not taken. All drugs for symptomatic migraine are more effective if taken when the pain is mild. However, patients often delay taking drugs, or they sometimes wake from sleep with intense pain or cannot retain the drug because of vomiting. As the pain progresses, central sensitisation can cause cutaneous allodynia (pain provoked by stimulation of the skin that would ordinarily not produce pain; this is seen especially in the head and face, but it can also be generalised) and triptans are unlikely to be effective. ${ }^{5}$

People with migraine often seek help in the emergency department, where they account for around $2 \%$ of visits and may receive a less than warm welcome when they present with "just a headache." In this setting evidence based guidelines recommend the first line use of dihydroergotamine, subcutaneous sumatriptan, dopamine antagonists (metoclopramide, prochlorperazine, and chlorpromazine), and ketorolac, which have response rates of up to $70 \%{ }^{6}$ However, narcotic analgesics, recommended as rescue drugs, are still widely used, even though their administration may result in significantly longer stays in the emergency department compared with non-narcotic treatments. ${ }^{7}$

Migraine pain persists or recurs within 24 hours of discharge from the emergency department regardless of treatment in over half of patients. ${ }^{8}$ Animal studies suggest that migraine pain may be caused by sterile inflammation in the nerves, which is why it was proposed that corticosteroids might reduce inflammation, relieve the pain, and prevent recurrence.

In their meta-analysis, Colman and colleagues included seven randomised controlled trials $(n=738)$ of intravenous dexamethasone (10-24 mg given once) for treatment of acute severe migraine headache and for preventing recurrence. ${ }^{1}$ There was no significant difference between dexamethasone and placebo for the immediate relief of acute migraine (weighted mean difference $0.37,95 \%$ confidence interval -0.20 to 0.94 ). However, when added to standard treatment, intravenous dexamethasone significantly reduced headache within 72 hours (relative risk $0.74,0.60$ to 0.90 ). Nine patients need to be treated to prevent one recurrent headache, a modest response.

Although side effects were minor and similar between groups, repeated doses in regular attendees to the emergency department may increase the long term risk for osteoporosis or, rarely, aseptic osteonecrosis of the femoral head or knees. ${ }^{9}$ Caution should be used when treating people with diabetes, who may have raised blood sugars during the 36-72 hour half life of dexamethasone.

Future research on corticosteroids might clarify the interaction with other drugs used to treat migraine; the optimum dose; whether oral administration is effective; and whether subgroups of people, such as those with prolonged severe headaches, may benefit in particular.

For now, we should try to keep patients out of the emergency department by encouraging them to treat their symptoms early on; making triptans, antiemetics, and rescue drugs more available as appropriate; and prescribing preventive drugs. An oral antagonist of calcitonin gene related protein, which may be available in the next couple of years, might provide better sustained pain-free responses at 24 hours than triptans. However, its use depends on regulatory approval and an acceptable safety profile, and it is unclear how effective it will be in people who do not respond to triptans. ${ }^{10}$ Doctors and migraine advocacy groups should lobby for increased government funding for migraine research, which, annually, is only about $\$ 13 \mathrm{~m}(£ 6.5 \mathrm{~m} ; € 8.2 \mathrm{~m})$ in the United States and $€ 6$ million in Europe. ${ }^{11}$

1 Colman I, Friedman BW, Brown MD, Innes GD, Grafstein E, Roberts TE, et al. Parenteral dexamethasone for acute severe migraine headache: meta-analysis of randomised controlled trials for preventing recurrence. BMJ 2008; doi: 10.1136/bmj.39566.806725.BE.

2 Lipton RB, Bigal ME, Diamond M, Freitag F, Reed ML, Stewart WF; American Migraine Prevalence and Prevention (AMPP) Advisory Group. Migraine prevalence, disease burden, and the need for preventive therapy. Neurology 2007;68:343-9.

3 Diamond S, Bigal ME, Silberstein S, Loder E, Reed M, Lipton RB. Patterns of diagnosis and acute and preventive treatment for migraine in the United States: results from the American migraine prevalence and prevention study. Headache 2007;47:355-63.

4 Diener HC, Limmroth V. Specific acute migraine treatment: ergotamine and triptans. In: Lipton R, Bigal M, eds. Migraine and other headache disorders: tools and rules for diagnosis and treatment. Ontario: BC Decker, 2006:289-310.

5 Bigal ME, Ashina S, Burstein R, Reed ML, Buse D, Serrano D, et al. Prevalence and characteristics of allodynia in headache sufferers: a population study. Neurology 2008;70:1525-33.

6 Ducharme J. Canadian Association of Emergency Physicians guidelines for the acute management of migraine headache. J Emerg Med 1999;17:137-44

7 Tornabene SV, Deutsch R, Davis DP, Chan TC, Vilke GM. Evaluating the use and timing of opioids for the treatment of migraine headaches in the emergency department. J Emerg Med 2008 Feb 13 [Epub ahead of print].

8 Friedman BW, Hochberg ML, Esses D, Grosberg BM, Rothberg D, Bernstein B, et al. Recurrence of primary headache disorders after emergency department discharge: frequency and predictors of poor pain and functional outcomes. Ann Emerg Med 2008 Apr 1 [Epub ahead of print].

9 Hussain A, Young WB. Steroids and aseptic osteonecrosis (AON) in migraine patients. Headache 2007;47:600-4.

10 Goadsby PJ. Calcitonin gene-related peptide (CGRP) antagonists and migraine: is this a new era? Neurology 2008;70:1300-1.

11 Shapiro RE, Goadsby PJ. The long drought: the dearth of public funding for headache research. Cephalalgia 2007;27:991-4. 


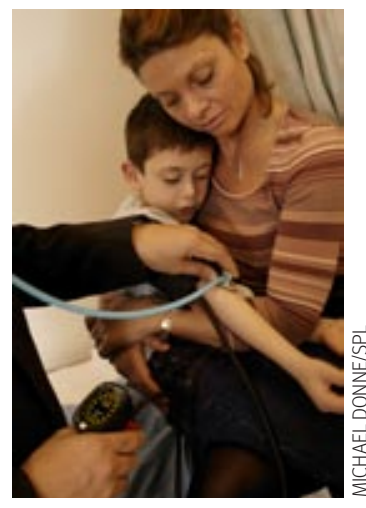

Chris Bird specialist training year 1, paediatrics, Ealing Hospital, Southall, London UB1 3HW chrisbird@doctors.org.uk Colin Michie consultant paediatrician, Ealing Hospital, Southall, London UB13HW Competing interests: None declared.

Provenance and peer reviewed: Not commissioned; externally peer reviewed.

BMJ 2008:336:1321 doi: 10.1136/bmj.a150

\title{
Measuring blood pressure in children
}

\author{
In theory should be routine, but in practice is rare
}

Although the theory behind measuring blood pressure in children is well known, in practice it is rarely done. One review stated that "measurement of blood pressure is now firmly established as an important component of the routine paediatric physical examination," but studies in practice prove otherwise. In the United States and Australia, between $5.3 \%$ and $66 \%$ of children attending emergency departments had their blood pressure measured, ${ }^{2-4}$ and in the United Kingdom this figure was about $9 \% .^{5}$ It is almost automatic to measure blood pressure in adults in the emergency department, so why are we so bad at doing this in children?

Firstly, measuring blood pressure in children is more difficult than in adults-for example, readings are likely to be falsely high in crying toddlers, normal ranges for blood pressure are often not displayed on the clinic wall, and an appropriately sized cuff may not be available in the triage room. Secondly, if a child is in shock, capillary refill time is easier and quicker to measure and, hopefully, acutely sick children would be identified before they become hypotensive because this is a preterminal sign. ${ }^{6}$ Thirdly, no clear definition exists on what constitutes abnormal blood pressure in children. ${ }^{7}$ Finally, clear guidance as to when blood pressure should be taken in triage is lacking.

Paediatric resuscitation guidelines make it clear that it is important to measure blood pressure when assessing a sick child's circulatory and neurological status: "Нypotension is a late and pre-terminal sign of circulatory failure. Once a child's blood pressure has fallen cardiac arrest is imminent. Hypertension can be the cause or result of coma and raised intracranial pressure."

The epidemic of childhood obesity makes it even more important to measure blood pressure. Rates have increased 2.0-2.8-fold over 10 years in the UK and 3.9-fold over 18 years in Egypt. ${ }^{9}$ In Australia, 23\% of children are overweight and $6 \%$ are obese. ${ }^{10}$

Childhood hypertension seems to track the growing rates of obesity in children, their reduced physical activity, and the development of maturity onset diabetes in this group. Jackson and colleagues produced new blood pressure centiles based on $23000 \mathrm{UK}$ children and found that high blood pressure is linked more to weight than height, after adjusting for age. ${ }^{7}$ They also estimated the prevalence of high blood pressure in UK children to be $2.3 \%$, and borderline "high normal" blood pressure to be $6.9 \%$ (they propose a new definition of hypertension for UK children as a blood pressure above the 98th centile, replacing the former measurement greater than the 95th centile, with a new definition of "high normal" lying between the 91 st and 98 th centiles). ${ }^{7}$ Hypertension in childhood may predict heart disease in later life, ${ }^{11}$ just as raised body mass index predicts coronary heart disease in adulthood. ${ }^{12}$

Measuring blood pressure is a cheap, relatively quick, and non-invasive way to screen for hypertension in children. Taking into account the Wilson criteria (the condition should be an important health problem; it should be detectable early on, so that primary prevention can be cost effective; and the pathophysiology and epidemiology should be well understood), it could be argued that all children with a raised body mass index should be screened by both a paediatrician and a general practitioner. Detecting hypertension at an early stage might improve the benefits of interventions like exercise and an improved diet.

Research is needed to establish more accurately what actually constitutes childhood hypertension and how best this might be detected given the demands made on already stretched health services. For example, a pilot screening programme in clinically obese children would be useful, with further research to investigate whether interventions to tackle childhood obesity actually reduce blood pressure and overall cardiovascular risk.

In the meantime, healthcare workers should be reminded of how simple it is to measure blood pressure in children. The cuff must cover at least two thirds of the right upper arm, between the olecranon and the acromion, with blood pressure readings from properly calibrated equipment measured against established centiles for age, sex, height, and weight. Measurement should be repeated at least twice when an abnormally high result is obtained.

We should ensure that optimal systems exist for measuring and recording blood pressure in children and tracking abnormal results. If we put as much effort into detecting and tracking abnormal blood pressure as we do for the follow-up of urinary tract infections in children, which can include ultrasound and dimercaptosuccinic acid (DMSA) scans, we might make a greater impact on the consequences of hypertension in later life and improve our care of acutely unwell children.

1 Sinaiko AR. Hypertension in children. NEngl J Med 1996;335:1968-73.

2 Pazdral PT, Lieberman H, Pazrdal W, Neumann CG, Lieberman E.

Awareness of pediatric hypertension: measuring blood pressure. JAMA 1976;235:2320-2.

3 Silverman MA, Walker AR, Nicolau DD, Bono MJ. The frequency of blood pressure measurements in children in four EDs. Am J Emerg Med 2000;18:784-8.

4 Gilhotra Y, Willis F. Blood pressure measurements on children in the emergency department. Emerg Med Australas 2006;18:148.

5 Burchell C, Michie CA. Blood pressure measurement in a district general paediatric A\&E department. Arch Dis Childhood 2005;90:1097.

6 McIntosh N, Helms P, Smyth RL, eds. Forfar and Arneil's textbook of paediatrics. 6th ed. Edinburgh: Churchill Livingstone, 2003.

7 Jackson LV, Thalange NKS, Cole TJ. Blood pressure centiles for Great Britain. Arch Dis Child 2007;92:298-303.

8 Mackway-Jones K, Molyneux E, Phillips B, Wieteska S, eds. Advanced paediatric life support: the practical approach. 4th ed. Oxford: Blackwell Publishing, 2005.

9 Ebbeling CB, Pawlak DB, Ludwig DS. Childhood obesity: public health crisis, common sense cure. Lancet 2002;360:473-82.

10 Waters EB, Baur LA. Childhood obesity: modernity's scourge. Med J Aust 2003;178:422-33.

11 Juonnala M, Viikari JSA, Ronnemaa T, Helenius H, Taittonen L, Raitakari OT. Elevated blood pressure in adolescent boys predicts endothelial dysfunction: the cardiovascular risk in young Finns study. Hypertension 2006;48:424-30

12 BakerJL, Olsen LW, Sorensen TIA. Childhood body-mass index and the risk of coronary heat disease in adulthood. NEngl/ Med 2007;357:2329-37. 


\section{The emergence of Stenotrophomonas maltophilia}

\section{Superbug or opportunist?}

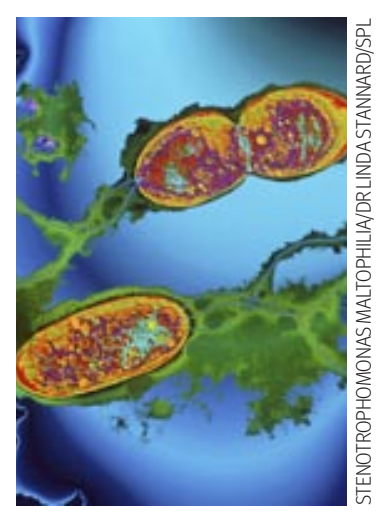

The recent publication of the genome sequence of the bacterium Stenotrophomonas maltophilia was accompanied by a press statement that described this organism as a "newly emerging superbug." 12 This was followed by a flurry of headlines in the United Kingdom informing the public of problems related to $S$ maltophilia, such as the apparent "rising death toll fear in hospitals" (Daily Mirror) and the concern of doctors that "no antibiotics can stop it" (the Sun). Suddenly, the public had a new superbug (or even "mega-bug", as it was referred to in the Sun) to worry about.

So, what must a bacterium do to earn "superbug" status? One prerequisite is resistance to multiple antibiotics and the associated difficulty in treating infections. Using this criterion, $S$ maltophilia is a strong candidate because it is inherently resistant to a wide range of antibiotics and can become more resistant by the acquisition of new genes. ${ }^{3}$ However, $S$ maltophilia infections are usually treatable because most isolates are susceptible to co-trimoxazole, which by consensus is the drug of choice. ${ }^{3}$ But it is worrying that effective treatment is limited to a single agent to which resistance has been reported, albeit rarely.

The other characteristic feature of the true superbug is its common occurrence, which reflects the ability to spread easily between patients and even between hospitals. In this regard, it is harder to accept the claim that $S$ maltophilia deserves the superbug epithet because this organism accounts for fewer than $1 \%$ of bloodstream infections. ${ }^{4}$ This is exemplified by comparison with the prevalence of the two pathogens with acknowledged superbug status-meticillin resistant Staphylococcus aureus (MRSA) and Clostridium difficile. Reports to the Health Protection Agency indicated that 4918 cases of bloodstream infection were caused by MRSA in England in 2007, ${ }^{5}$ compared with 671 reports of $S$ maltophilia. ${ }^{6}$ Although MRSA and $S$ maltophilia cause other infections besides bacteraemia, the relative occurrence is likely to be similar. These data also contrast with more than 50000 reported cases of gastrointestinal infections caused by $C$ difficile. ${ }^{5}$

Outbreaks of MRSA and $C$ difficile are well described and strains of each species with epidemic potential have been identified. In contrast, $S$ maltophilia is of limited pathogenicity and infections in previously healthy patients are unusual. Furthermore, when it is isolated from patients' specimens, it is often unclear whether this reflects colonisation or contamination. It most often affects patients in critical care units or oncology units, usually those with comorbidities, those who have previously received multiple courses of antimicrobials, or those being ventilated. It may cause long term colonisation in patients with cystic fibrosis. It does not readily spread between patients, and acquisition is usually from environmental sources, particularly moist ones such as water, aqueous solutions, nebulisers, or mechanical ventilators. In these circumstances, it is more deserving of the "opportunist" rather than "superbug" title.

Although in public health terms the burden of disease as a result of $S$ maltophilia is relatively low compared with the many other species of bacteria, fungi, and viruses that cause healthcare associated infections, this is of little consolation to people who develop infections with this organism. So what can be done? Large scale interventions aimed specifically at preventing infection with $S$ maltophilia are unlikely to be initiated because many other pathogens have greater clinical importance in terms of their frequency and the limited therapeutic options. However, many initiatives and interventions aimed at curbing the spread of these other organisms will also affect $S$ maltophilia because the risk factors for colonisation or infection are often similar. Interventions such as improved hospital hygiene, improved attention to line insertion to prevent line associated bacteraemia, and antibiotic stewardship aimed at reducing the pressure for emergence and spread of strains of antibiotic resistant bacteria are all microbiologically non-specific and will affect a wide range of pathogens. ${ }^{7}$

The current high degree of concern about $S$ maltophilia stemmed from the press release about the characterisation of the organism's genome. We hope that this new knowledge of the organism's biology will help allay these concerns by being used to improve diagnostic tests, identify new drug targets, or even develop a vaccine, which could reduce the burden of disease caused by this little known pathogen.

1 Crossman L, Gould VC, Dow JM, Vernikos GS, Okazaki A, Sebaihia $M$, et al. The complete genome, comparative and functional analysis of Stenotrophomonas maltophilia reveals an organism heavily shielded by drug resistance determinants. Genome Biol 2008;17;9:R74.

2 Wellcome Trust. Genome sequence of emerging superbug reveals high degree of drug resistance. 2008. www.wellcome.ac.uk/ News/News-archive/Browse-by-date/2008/News/WTD040141. htm.

3 Nicodemo AC, Garcia Paez JI. Antimicrobial therapy for Stenotrophomonas maltophilia infections. Eur J Clin Microbiol Infect Dis 2007;26:229-37.

4 Health Protection Agency. Polymicrobial bacteraemias and fungaemias in England, Wales, and Northern Ireland: 2006-total reports. 2008. www.hpa.org.uk/web/HPAweb\&HPAwebStandard/ HPAweb_C/1195733810096.

5 Health Protection Agency. Quarterly reporting results for Clostridium difficile infections and MRSA bacteraemia. April 2008. www.hpa.org.uk/web/HPAweb\&Page\&HPAwebAutoListName/ Page/1191942126541.

6 Health Protection Agency. Health protection report. Pseudomonas spp. and Stenotrophomonas maltophilia bacteraemia in England, Wales, and Northern Ireland, 2003 to 2007. 2008. www.hpa.org. uk/hpr/infections/bacteraemia.htm.

7 Owens RC Jr. Antimicrobial stewardship: concepts and strategies in the 21st century. Diagn Microbiol Infect Dis 2008;61:110-28. 